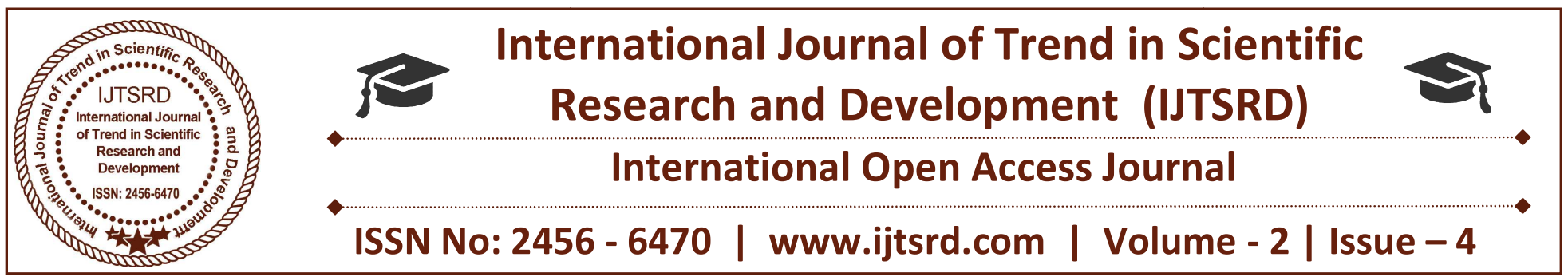

\title{
Modelling and Analysis of Grid Connected PV System under Different Penetration Level of PV
}

\author{
Javeed Ahmad Khan \\ M.Tech Scholar, Electrical Engineering Department, \\ Yamuna Institute of Engineering \& Technology, Gadhauli, Yamunanagar, Haryana, India
}

\section{ABSTRACT}

In the last two decades there is very sharp rise in the power generation from the solar system. This is due to the increasing solar cell efficiency, decreasing PV system costs, increasing government support, and many other factors collectively help in reduce the barriers of growth for PV systems to expand their participation to the total world energy sector. The drawbacks of the inverters which are currently used in grid connected PV system are well known. As the penetration of PV system is increasing day by day this problem is becoming more significant. This paper provide a solution in the control of inverter by regulating the active power and reactive power. The proposed control scheme helps in providing grid support by PV system as well as reducing the harmonics contents in the power hence improving power quality. The design, modeling, and analysis of a grid-tied PV system was performed in the MATLAB software simulation environment. Results indicate that in the presence of grid disturbances the proposed inverter can react dynamically to help restore the power system back to its normal state. A harmonic analysis was also performed indicating the inverter under study met the applicable power quality standards for distributed energy resources.

\section{INTRODUCTION}

Electricity generation using photovoltaic (PV) systems is clean, reliable and has the potential to play a significant role in mitigating $\mathrm{CO}_{2}$ emissions. Considering the potential for cost reduction of PV systems and increase in their efficiency, it is envisaged that PV will become one of the major future sources of electricity generation. Global PV electricity generating technology has shown an impressive annual growth with an annual total of 920 GW new installations is expected to be registered in 2022 [1]. The global PV installed capacity at end of 2016 was estimated at more than 303 GW [1]. Knowledge on the energy yield performance of a PV system in a given location is important in designing a suitable system for a particular application. A number of commercial software packages are available for predicting PV system performance at a location of interest. These software packages use meteorological databases, PV module and inverter data to predict the energy yield of PV systems. There are multiple types of materials used in the manufacturing of PV cells, all with different efficiencies, but the general trend is that they are all increasing. PV cell materials are not chosen simply because they boast the greatest efficiency. The best materials for PV cells offer the greatest cost to efficiency tradeoffs. An example of this is that thin film technology has a lower efficiency than crystalline silicon cells, however due to the lower cost, it is more effective in some cases to mass produce the less efficient cell.

Currently, the large increase in distributed generation has caused a different effect on the voltage profile. When the grid connected distributed resources, solar for example, inject more power to the grid than the local area needs the voltage tends to rise in that area [2]. The voltage profile is most impacted when the injected power of the grid tied resource is greater than the load on its feeder [3]. A rising, or swelling voltage profile can also occur during light loading conditions. 
A combination of light loading and large generation, easily realizable for solar power when people are at work during the day and the sun is shining its brightest, can have a significant influence on the feeder voltage [4]. In some cases the voltage rises to a level such that it becomes greater than specified limits and certain generation systems have to be disconnected from the grid, wasting potential clean renewable energy production [5]. Solutions to help support voltage and frequency at the distribution level range from simple to sophisticate. The primary concern at this lower level is the voltage regulation. Frequency is less of a concern far away from large generating sources because the system frequency is the same everywhere along the transmission and distribution lines whereas the voltage is not. Further, the ratio of a typical feeder load compared to the power capability of the connected grid is typically small, meaning the system frequency cannot be greatly influenced by variations on that feeder. When frequency is below or above the nominal value the solution is not typically implemented at the distribution level but instead larger power plants that play a greater role in frequency regulation are controlled to either increase or decrease their generation to maintain it [11]. However, as sources continue to emerge locally at the distribution level, such as residential PV, it will not be long until their collective generation will be able to modify the system frequency.

\section{GRID CODES AND REGULATIONS}

In order to exchange power with the grid certain requirement must be met to ensure the quality and stability of the power system is maintained. The standards for connecting distributed resources with an electric power system are defined in IEEE 1547 . The IEEE 1547 standard was originally created in 2003 and since then many subsequent versions have been released and some are still under draft [7]. The main drawback of the standard is that when created it was just the beginning of the rapid growth in photovoltaic and other distributed resources. Certain provisions were outlawed that now due to increasing PV penetration and advancements in power electronics can be seen as necessary and easily implemented functions. One, and arguably the most controversial, provision is that these resources should not regulate the voltage at the point of common coupling (PCC) [9].

As discussed in the background section of this study, increasing levels of PV can have adverse effects on a power systems voltage and different equipment has been installed to counteract it. Allowing the inverter or other power conversion devices to help the voltage problem they create by generating or absorbing the required reactive power to maintain nominal voltage at the PCC is a main attribute of the inverter in this design. Obviously, this goes directly against the IEEE 1547 standard but by providing the necessary simulation results of this study one hopes this control strategy can be adopted as a viable solution to the voltage problem. The distributed resource interconnection standard has also outlined specific allowable limits for voltage and frequency of the power system the distributed resources are connected to. If the specified limits are exceeded the distributed resource must disconnect from the grid within the maximum clearing time if the disturbance is still present. The voltage limits and clearing times are shown in Table 1. These limits were put into place to eliminate unwanted grid islands from forming when neighboring power lines are tripped off and for safety when disturbances are present. The operational limits in the tables will be used during the design and testing of the proposed inverter.

Table I. I. Interconnection System Response to Abnormal Voltages

\begin{tabular}{|l|l|}
\hline $\begin{array}{c}\text { Voltage Range (\% of the } \\
\text { base voltage) }\end{array}$ & \multicolumn{1}{|c|}{$\begin{array}{c}\text { Clearing Time } \\
\text { (s) }\end{array}$} \\
\hline $\mathbf{V}<\mathbf{5 0 0 . 1 6}$ & 0.16 \\
\hline $\mathbf{5 0} \leq \mathbf{V}<\mathbf{8 8 ~ 2}$ & 2 \\
\hline $\mathbf{1 1 0}<\mathbf{V}<\mathbf{1 2 0} 1$ & 1 \\
\hline $\mathbf{V} \geq \mathbf{1 2 0 ~ 0 . 1 6}$ & 0.16 \\
\hline
\end{tabular}

\section{MODELLING OF PV SYSTEM}

Solar cell can be modelled as current source (Iph) in parallel with Diode (D), Shunt resistance (Rsh) and series resistance (Rse).Current and voltage profile of the solar cell depends on Atmosphere temperature (T), and irradiance (S). The output power of Photo voltaic cell is given by $\mathrm{P}=\mathrm{V}^{*} \mathrm{I}$. The current produced by the PV cell is equal to the current produced by the current source minus the diode and shunt resistance current. The light generated current of Photo voltaic cell depends on the solar irradiation and the temperature. 
$I=I p h-I d-I s h$

$I p h=[I S C+K i *(T-T r)] * \frac{S}{1000}$

$I d=I o\left(e^{\frac{q\left(v+i^{*} R s\right.}{A K T}}-1\right)$

$I o=I o r\left(\frac{T}{T r}\right)^{3} *\left(e^{\frac{q^{*} E g^{*}\left(\frac{1}{T r}-\frac{1}{T}\right)}{A^{*} K}}\right)$

$\mathrm{I}=$ Output current

$\mathrm{Iph}=$ cell generated current

$\mathrm{Id}=$ Diode current

Ish=current drawn by the shunt resistance

$\mathrm{Ki}=$ short circuit temp coefficient of cell $(0.0032 \mathrm{~A} / \mathrm{k}$ (approx.)) $\mathrm{T}=$ module operating temperature in kelvin

$\operatorname{Tr}=$ reference temperature in kelvin $=298 \mathrm{k}$

$\mathrm{Q}=$ charge of electron $=1.9 * 10^{-19}$

$\mathrm{S}=$ module irradiance $\left(\omega / \mathrm{m}^{2}\right)$

$\mathrm{K}=$ Boltzmann constant $=1.38 * 10^{-23}$

The important parameters of solar cell are open circuit voltage (Voc), short circuit current (Isc), Maximum Output power (Pmax).

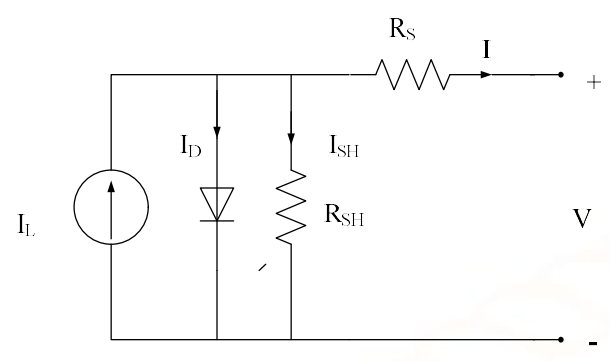

Fig. 1. Equivalent circuit of PV cell

Here is the source current or the solar cell current which is of nearly constant. Id is the diode current, Diode is placed in parallel to ground the cells which are which are effected by the unshaded portion of the sun irradiation. $R_{s h}$ is to to represent the leakage current that is presented in the cell which is the order of $1000 \mathrm{ohms}$. Rse is the series resistance to replace the losses present the cell. Vo is the output voltage or the open circuit voltage presented, at the terminals of the cell. Io is the current available at the output of the cell. The equivalent circuit of the solar cell is shown in Fig. 1 .

The source current generated the cell is constant, as and when the temperature are constant. As the current generated by the cell depends on the temperature and the solar irradiation. The diode current has the steeply increasing characteristics, with the voltage. The output current is the combination of cell current and the diode current, it results in the nonlinear characteristics of the output current and the voltage.

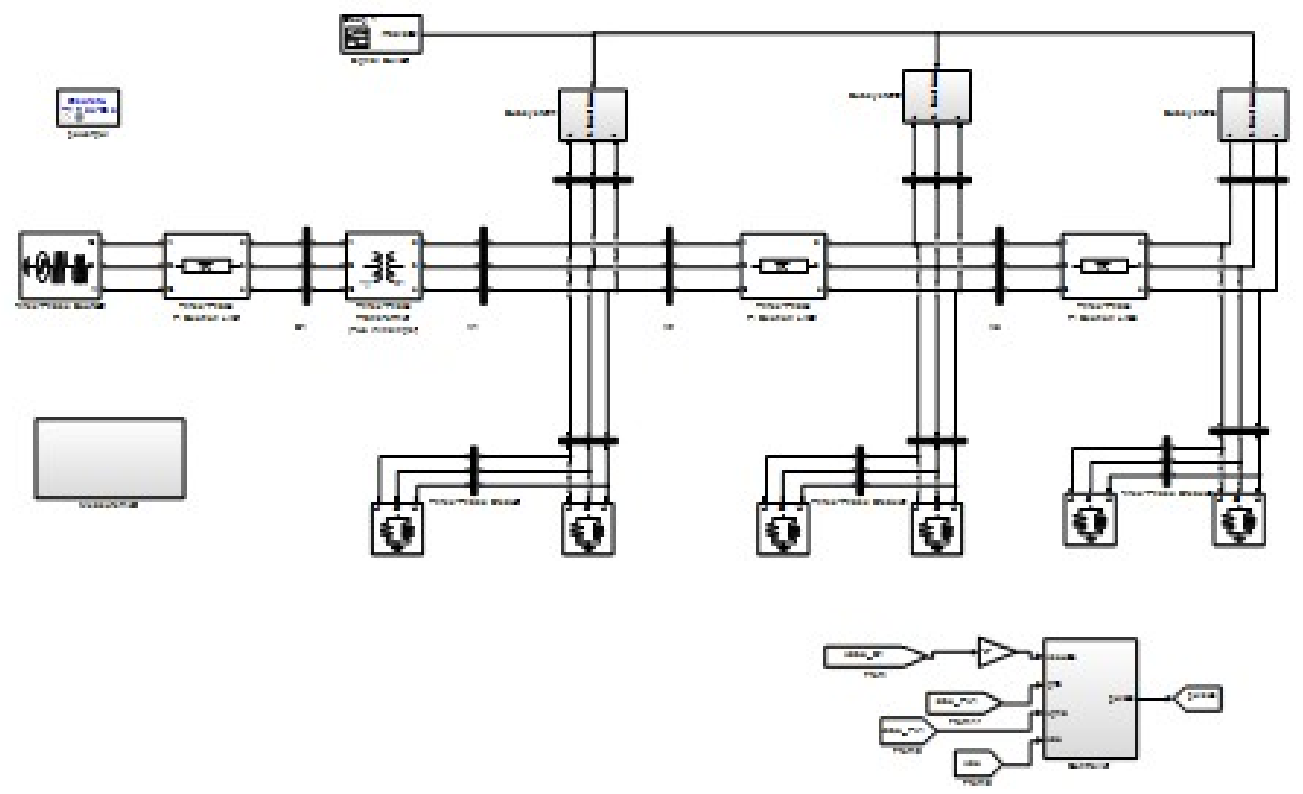

Fig. 2. Simulink model of grid connected PV system 


\section{RESULTS AND DISCUSSION}

This section gives the simulation MATLAB results about the work that has been done. It gives the results about the photovoltaic cell characteristics, and the dependence of the results on the atmosphere conditions like temperature and irradiation. The results of the boost converter applying maximum power tracking technique, involving input and output voltage from the converter. It describes about the results relating to linear and nonlinear loads after applying $\mathrm{P} \& \mathrm{O}$ method of MPPT to the inverter and gives the results about the total harmonic results level.

The grid voltage is $22 \mathrm{KV}$ and the system is connected to the purely resistive load. There are three solar panels are connected to the grid through stardelta transformer. The system is connected to three set of three phase load. The three phase load has minimum and maximum values is $14.65 \mathrm{KW}$ and $25.95 \mathrm{KW}$ respectively. The load connected here is assumed to be purely resistive load so reactive power requirement is almost zero. The small amount of reactive power drawn by the system is of coupling inductors, transformer reactance and line inductance.

The grid connected PV system is subjected to different perturbances such as continuously variable load and variable irradiance level. In this work the system is studied under these two perturbances. The two cases are formed to analyze the system performance, these are:

1. Change in irradiance level.

2. Change in the value of three phase load.

The simulation is done for the two seconds and divided in the two parts of one second each. In the first part the irradiation level is changed. From the time $0 \mathrm{sec} .-0.3 \mathrm{sec}$ the irradiance level is $600 \mathrm{KW} / \mathrm{m}^{2}$, from time $0.3 \mathrm{sec}$. to $0.5 \mathrm{sec}$. it is $700 \mathrm{KW} / \mathrm{m}^{2}$, from 0.5 to 0.6 it is $800 \mathrm{KW} / \mathrm{m}^{2}$ and from time $0.6 \mathrm{sec}$. to $2.0 \mathrm{sec}$. the irradiance level is $1000 \mathrm{KW} / \mathrm{m}^{2}$.

For the second case the value of the three phase load is change in the second part of the simulation i.e. at time 1.5 second and load is made double $(14.65 \mathrm{KW}$ to $25.95 \mathrm{KW}$ ). The system is again checked for another two cases, these are:

1. Minimum irradiance level and maximum load.

2. Maximum irradiance level and minimum load.

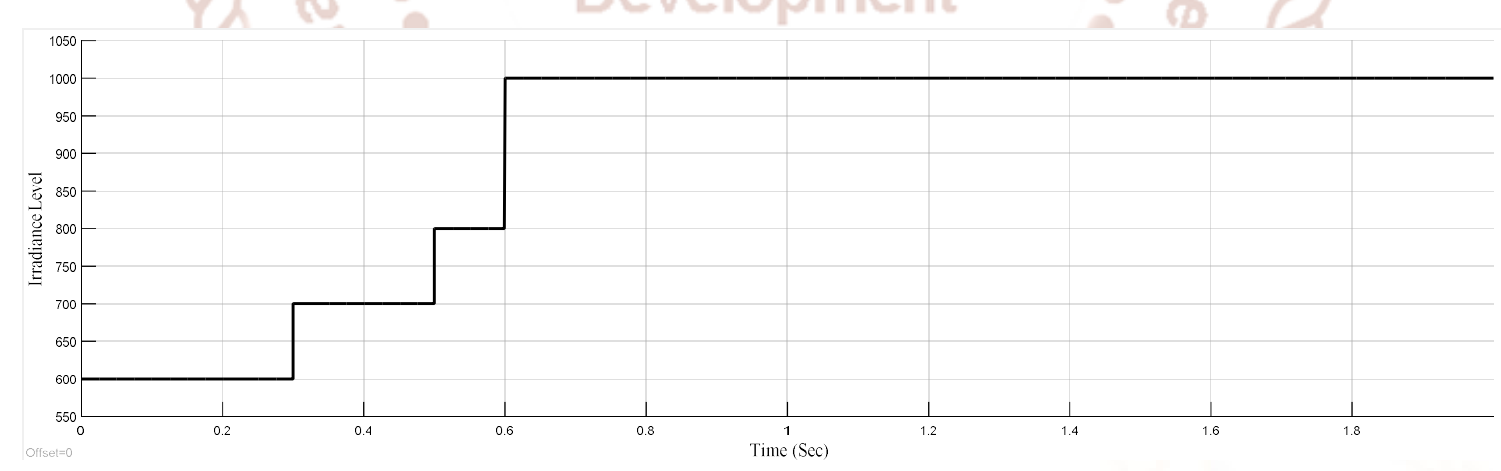

Fig. 3. Irradiance level

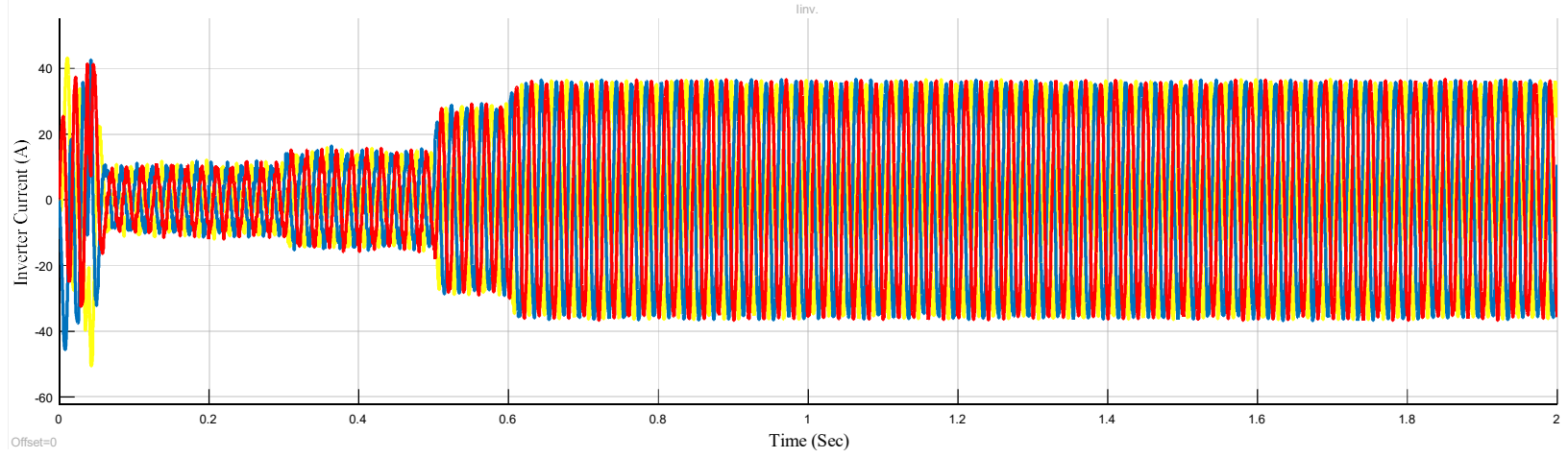

Fig. 4. Three phase inverter current 


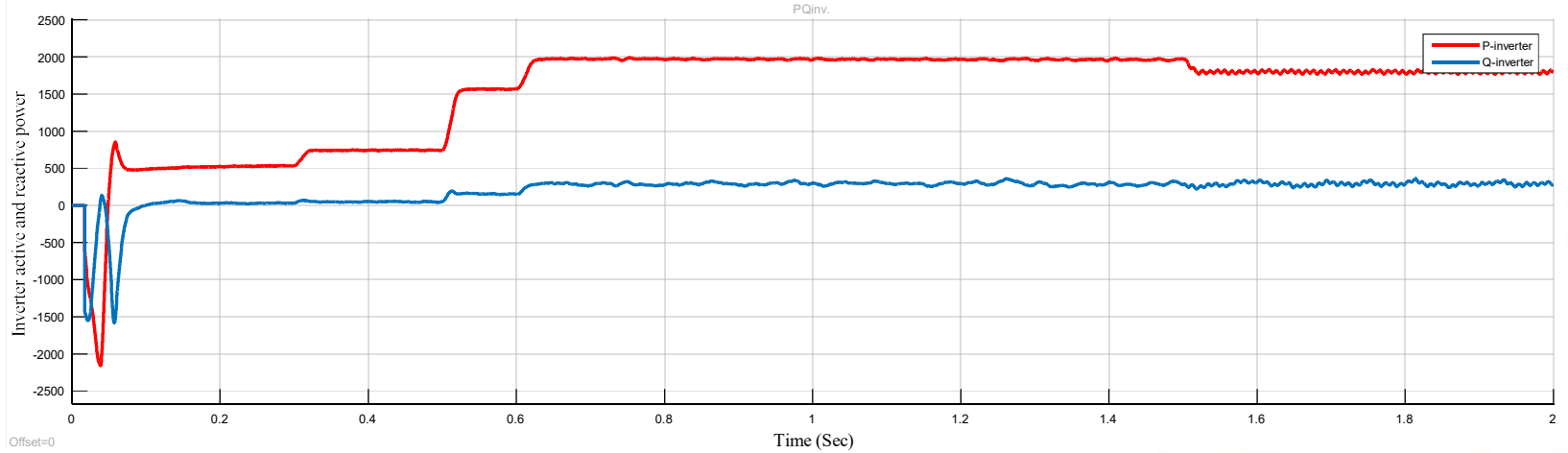

Fig. 5. Inverter active and reactive power

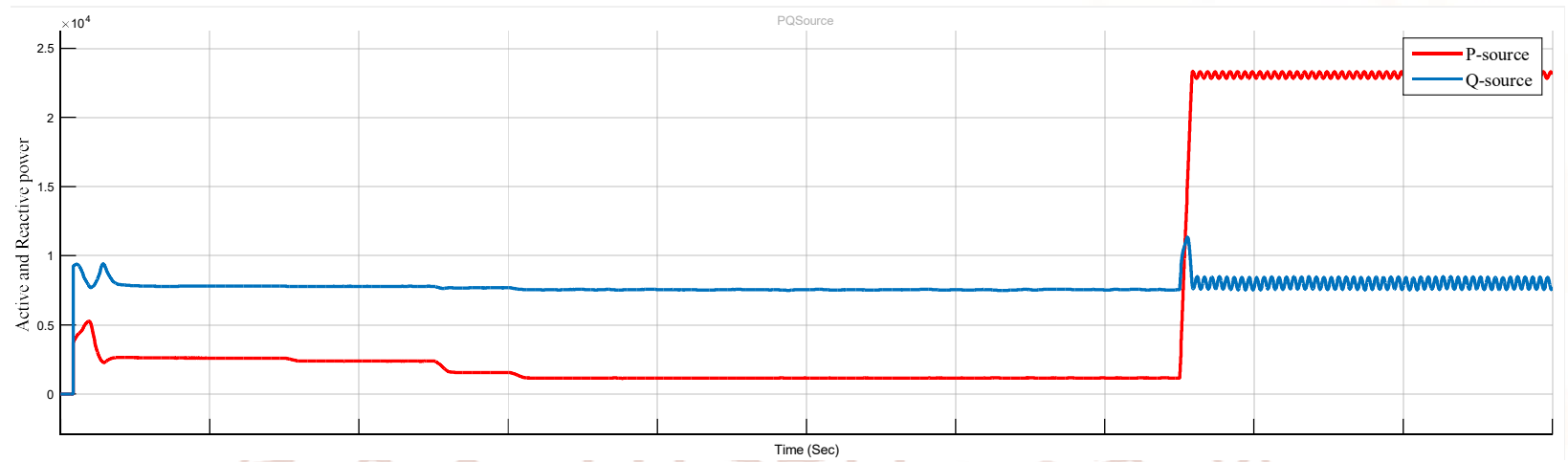

Fig. 6 Source active and reactive power
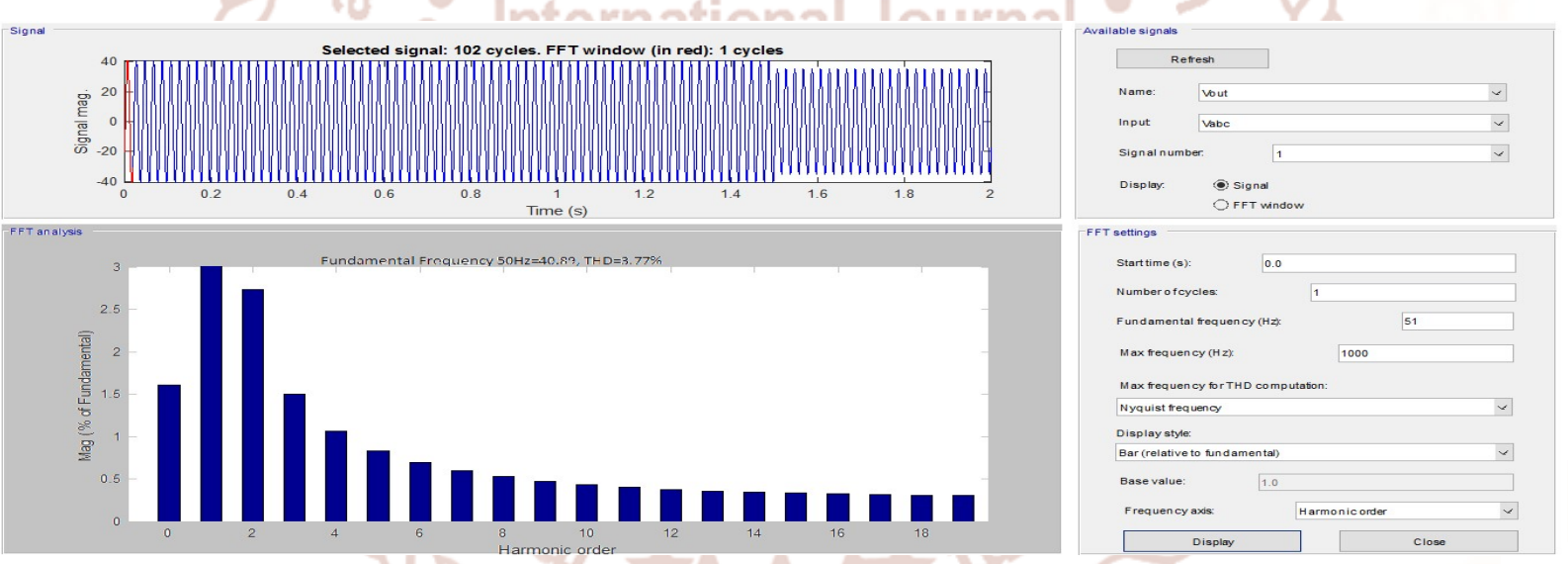

Fig. 7 THD analysis of grid connected PV system.

\section{Conclusions}

This work gives the modeling and simulation of grid connected solar power system. And the output voltage and current, output power versus voltage are observed at different irradiance and load conditions. The maximum power variation with the parameters are observed. The MPPT techniques for photovoltaic cells are developed and the output characteristics are observed at different irradiance level are observed. The boost converter applying the maximum power point technique based on $\mathrm{P} \& \mathrm{O}$ method is explained. The operation of boost converter at different operating conditions like turn on and turn off conditions are observed. The input and output voltages applied for the boost converter are shown and its importance is explained. The combination of boost converter with maximum power point tracking controller makes the converter to obtain the maximum power from solar cell. The operation of the inverter is explained with its different operating modes are the graphs for currentvoltage and power to voltage are observed under different methods. 


\section{REFERENCES}

1) Renewable Energy Policy Framework (REN21). Global status report 2017. Technical report, Paris; 2017.

2) PVsyst. Photovoltaic and simulation program, version 6.2 .

3) eteonorm. Global meteorological database version 7.1.1.

4) IEC standard 61724. Photovoltaic system performance monitoring- guidelines for measurement, data exchange and analysis. Technical report, IEC Geneva, Switzerland; 1998.

5) Ayompe LM, Duffy A, McCormack SJ, Conlon M. Measured performance of a $1.72 \mathrm{~kW}$ rooftop grid-connected photovoltaic system in Ireland. Energy Convers Manage 2011;52(2):816-25.

6) Congedo PM, Malvoni M, Mele M, De Giorgi MG. Performance measurements of monocrystalline silicon PV modules in southeastern Italy. Energy Convers Manage 2013;68:110 .

7) Sharma Vikrant, Chandel SS. Performance analysis of a $190 \mathrm{kWp}$ grid interactive solar photovoltaic power plant in India. Energy 2013;55:476-85

8) Kymakis E, Kalykakis S, Papazoglou TM. Performance analysis of a grid connected photovoltaic park on the Island of Crete. Energy Convers Manage 2009;50:433-8.

9) Padmavathi K, Daniel SA. Performance analysis of a $3 \mathrm{MWp}$ grid connected solar photovoltaic power plant in India. Energy Sustainable Dev 2013;17:615-25.

10) Sidrach de Cardona M, Li Mara L. Evaluation of a grid connected system in southern Spain. Renewable Energy 1997;15:527-30.

11) Micheli D, Alessandrini S, Robert Radu, Casula I. Analysis of the outdoor performance and efficiency of two grid connected photovoltaic systems in northern Italy. Energy Convers Manage 2014;80:436-45.

12) SAURAN. Southern African Universities Radiometric Network. Solar radiometric data for public.

(1)

